\title{
EDITORIAL
}

\section{Significado del trabajo y salud en pandemia}

\section{Meaning of work and health in pandemic}

\author{
Lilibeth Patricia Pedraza-Alvarez (D)1, Kelly Obispo-Salazar (D)2 \\ 1. Universidad del Magdalena. Santa Marta, Universidad del Valle. Cali, Colombia. Correo: Ipedraza@unimagdalena.edu.co - \\ https://orcid.org/0000-0002-5963-3131 \\ 2. Universidad del Magdalena. Santa Marta, Universidad del Valle. Cali, Colombia. Correo: kobispo@unimagdalena.edu.co - \\ https://orcid.org/0000-0003-3618-1192
}

El trabajo siempre ha estado inmerso en la vida del hombre, hasta el punto que distintos autores destacan la importancia de este en la vida de las personas como en el caso de Guerra ${ }^{1}$ quien indican que no se puede concebir al hombre sin el trabajo o Jahoda $^{2}$ para quien el trabajo es la propia esencia de estar vivo o más recientemente Blanch $^{3}$ que señala que el trabajo enmarca los diferentes aspectos de la humanidad como son: económico, social, político, cultural, urbano, moral, jurídico y psicológico por lo que estudiar el trabajo se convierte en un tema de interés para muchos y por lo tanto ha sido estudiado desde distintos contextos.

Es de destacar que no solo es importante estudiar el trabajo como fundante del ser humano sino lo que ha sido el trabajo para este, es decir, el significado que ha tomado para las personas el hecho de trabajar. El Meaning of Work International Research Team - MOW ${ }^{4}$ habló sobre el concepto del significado del trabajo como un constructo psicológico multidimensional y dinámico, formado de la interacción entre variables personales y ambientales e influenciado por los cambios en el individuo a su alrededor o en el trabajo, lo que permite ver como el significado del trabajo puede variar de una persona a otra teniendo en cuenta el contexto de cada individuo y su ciclo de vida, en ese sentido Rentería ${ }^{5}$ también hace referencia a como todas las etapas del ciclo de vida como infancia, adolescencia, juventud, adultez y vejez están claramente marcados por la expectativa de que el trabajo sea la actividad principal en la época de adultez, evidenciando un alto grado de importancia de lo que significa el trabajo para las personas.

Hoy es necesario destacar que el contexto ha cambiado para toda la humanidad al tener que afrontar la pandemia ocasionada por la COVID-19 pues esta ha tenido un impacto no solo en la salud de las personas sino en el trabajo y las relaciones al interior del trabajo, el Observatorio de la $\mathrm{OIT}^{6}$ publicó en un informe el 25 de enero de 2021 que en 2020 se perdió el 8,8 por ciento de las horas de trabajo a nivel mundial con respecto al cuarto trimestre de 2019, equivalente a 255 millones de empleos a tiempo completo, además señaló que la pérdida de horas de trabajo fue particularmente elevada en América Latina y el Caribe, Europa meridional y Asia meridional, llegó al punto de que la pérdida de horas de trabajo en 2020 fue aproximadamente cuatro veces mayor que la registrada durante la crisis financiera mundial de 2009.

Por otro lado, las personas han tenido que modificar sus hábitos de trabajo al tener que llevarlo a casa o al tener que acondicionar los espacios de trabajo para mantener las medidas de bioseguridad, los mismos gobiernos han tenido que pronunciarse sobre esta necesidad al buscar mantener la salud pública. Colombia no ha sido la excepción y el Ministerio del Interior a través del Decreto 1168 del 25 de agosto de $2020^{7}$ reguló la fase de aislamiento selectivo y distanciamiento individual responsable, donde en el artículo 8 estableció el "Teletrabajo y trabajo en casa. Durante el tiempo que dure la 
emergencia sanitaria por causa de la pandemia del Coronavirus COVID-19, las entidades del sector público y privado procurarán que sus empleados o contratistas cuya presencia no sea indispensable en la sede de trabajo, desarrollen las funciones y obligaciones bajo las modalidades de teletrabajo, trabajo en casa u otras similares." Lo cual hasta el momento se ha mantenido en muchos empleos como por ejemplo el de los docentes que han desarrollado sus actividades desde casa con el uso de la virtualidad.

Esto ha repercutido en las familias y en la crianza de los hijos y su cuidados, hasta el punto que la UNICEF ${ }^{8}$ generó un informe con una serie de recomendaciones para combinar el trabajo en casa con el cuidado de los niños, reconociendo que los trabajadores han tenido que asumir diferentes roles y responsabilidades desde la casa sumados a sus actividades de trabajo como acompañamiento a los niños en su educación, cuidado de la salud de la familia, tareas del hogar, resolver el abastecimiento de víveres y alimentos, cuidado y crianza de los niños y niñas, además de afrontar la incertidumbre de lo que pasará.

Todas estas situaciones han llevado a que se tenga que prestar atención a otro tema, a la salud mental, pues el disconfor que ha generado los cambios de rutinas y hábitos de vida, el cumplir con diferentes tareas o roles en un mismo espacio físico y de tiempo, la incertidumbre, y el temor al desempleo por no poder cubrir los requerimientos personales $y$ familiares, sumado al temor por contraer el virus y tener que afrontar la enfermedad o muerte de un familiar genera altos niveles de estrés. $\mathrm{La} \mathrm{OMS}^{9}$ en un comunicado del 5 de octubre de 2020 destacó que la pandemia está provocando un incremento de la demanda de servicios de salud mental. El duelo, el aislamiento, la pérdida de ingresos y el miedo están generando o agravando trastornos de salud mental. Muchas personas han aumentado su consumo de alcohol o drogas y sufren crecientes problemas de insomnio y ansiedad.

Todo esto puede de una u otra forma repercutir en el desarrollo de su trabajo y en el significado que se le esté dando al mismo, pues este podría verse o percibirse como una carga que se suma a todas las responsabilidades que se deben asumir durante la pandemia y que puede generar agotamiento, debido a que los horarios de trabajo ya no son tan claros pues las personas teniendo su trabajo en casa pueden dar inicio más temprano e incluso terminar más tarde, la virtualidad ha llevado a muchos a tener que estar presente en distintos lugares al tiempo pues son citados a reuniones distintas en un mismo horario y parece que las personas tuvieran la sensación de no poderse negar a estar en alguna, además esos límites entre los tiempos de trabajo y los tiempos de familia se han superpuesto pues aun cuando están en horas laborales no se puede olvidar que ahora están en casa y los hijos reclaman cuidados y atención que hace que las personas deban desarrollar labores propias de su rol de padre o de familia en tiempos que antes eran considerados del trabajo, todos los miembros de la familia están en casa conectados al internet y en diálogos simultáneos que se pueden cruzar los unos con los otros y que el silencio o los bajos niveles de ruido antes cuidado en las oficinas hoy se hace imposible mantener en casa convirtiéndose en un estresor, cambiando entonces la connotación del trabajo. Por otro lado, puede estar una visión positiva o un significado más positivo del mismo cuando al ver como muchos hogares han sido golpeados por el desempleo dada las condiciones de la pandemia, tener un empleo y poder suplir sus necesidades y aún mantener, aunque sea de manera virtual las relaciones con sus jefes y compañeros de trabajo se convierte en muy valorado

\section{DECLARACIÓN SOBRE CONFLICTOS DE INTERÉS}

Ninguno que declarar.

\section{REFERENCIAS BIBLIOGRÁFICAS}

1. Guerra P A. Sociología del trabajo. Fundación de Cultura Universitaria; 1998. Disponible en: https://www.zonalegal.net/uploads/documento/G UERRA\%20Sociologia\%20del\%20trabajo.pdf

2. Jahoda M. Empleo y desempleo: un análisis sociopsicológico. Ediciones Morata; 1987. [Consultado el 6 de abril de 2021]. Disponible en: https://eprints.ucm.es/id/eprint/41337/1/empleo 
\%20y\%20desempleo.\%20un\%20analisis\%20sociopsicologico.pdf

3. Blanch J. Trabajar en la modernidad industrial. En J. Blanch, M. Espuny, C. Gala y A. Artiles (Eds). Teoría de las relaciones laborales. Fundamentos (pp. 19148). Barcelona, España: Editorial UOC; 2003. [Consultado el 3 de mayo de 2021]. Disponible en https://books.google.com.co/books?id=te_jmaDDagC\&pg=PA99\&dq=Josep+blanch+fundamen tos.+teor\%C3\%ADas+de+las+relaciones+laborales\& $\mathrm{hl}=\mathrm{es}-$

419\&sa=X\&ved=2ahUKEwjTt8uHqo3yAhXaRjABHV UWDNsQ6AEwAXoECAUQAg\#v=onepage\&q=Josep \%20blanch\%20fundamentos.\%20teor\%C3\%ADas\%2 Ode\%20las\%20relaciones\%20laborales $\& \mathrm{f}=$ false

4. Meaning of Work International Research Team. The meaning of working. Academic Press; 1987. Doi: https://doi.org/10.1515/9783110863659-028

5. Rentería E. Nuevas realidades organizacionales y del mundo del trabajo: implicaciones para la construcción de la identidad o del sujeto. Informes psicológicos. 2008; 10: 65-80. Disponible en https://revistas.upb.edu.co/index.php/informespsi cologicos/article/view/931

6. Organización Internacional del Trabajo- OIT. La COVID-19 y el mundo del trabajo. Séptima edición Estimaciones actualizadas y análisis; 2021. Disponible en: https://www.ilo.org/wcmsp5/groups/public/--dgreports/--dcomm/documents/briefingnote/wcms_767045.pd $f$

7. Ministerio del Interior de Colombia. Decreto 1168 del 25 de agosto de 2020. Por el cual se imparten instrucciones en virtud de la emergencia sanitaria generada por la pandemia del Coronavirus COVID 19, y el mantenimiento del orden público y se decreta el aislamiento selectivo con distanciamiento individual responsable. [Consultado el 3 de mayo de 2021]. Disponible en https://dapre.presidencia.gov.co/normativa/norma tiva/DECRETO\%201168\%20DEL\%2025\%20DE\%20A GOSTO\%20DE\%202020.pdf
8. Fondo de las Naciones Unidas para la Infancia. (UNICEF). Recomendaciones a las familias para combinar el trabajo desde casa con el cuidado de los niños pequeños; 2020. [Consultado el 5 de mayo de 2021]. Disponible en https://www.unicef.org/lac/media/11081/file/Tele trabajo-y-cuidado-de-los-ninos-covid19.pdf

9. Organización Mundial de la Salud (OMS). Los servicios de salud mental se están viendo perturbados por la COVID-19 en la mayoría de los países, según un estudio de la OMS; 2020. [Consultado el 4 de mayo de 2021]. Disponible en: https://www.who.int/es/news/item/05-10-2020covid-19-disrupting-mental-health-services-inmost-countries-who-survey 